\title{
Um Entre Muitos: instituições de ensino superior em um ecossistema de pedagogias urbanas
}

\author{
Geetika Anand' \\ Ruchika Lall' \\ Julia Wesely" \\ Adriana Allen"
}

'Indian Institute for Human Settlements, Bangalore - Índia "University College London, Londres - Reino Unido

RESUMO - Um Entre Muitos: instituições de ensino superior em um ecossistema de pedagogias urbanas. Este artigo examina como e por que os educadores das universidades podem e precisam trabalhar como 'um entre muitos' para propor pedagogias críticas para a igualdade urbana. A discussão está embasada em duas experiências distintas: as escolas em rede da Habitat International Coalition América Latina (HIC-AL) - uma coalizão de organizações da sociedade civil, movimentos sociais e universidades que trabalham pela defesa de direitos humanos relacionados à moradia - e os processos de coaprendizagem com ativistas pelos direitos à moradia facilitados pelo Indian Institute for $\mathrm{Hu}$ man Settlements (IIHS) - uma instituição educacional nacional comprometida com a transformação igualitária, sustentável e eficiente dos assentamentos na Índia. Ambas as experiências enfatizam a criação de pedagogias críticas que procuram fundamentalmente romper, reformular e reposicionar relações institucionais de saberes e práticas de aprendizagem ao propor capacidades para uma transformação urbana transformadora. A análise demonstra como as injustiças epistêmicas - muitas vezes proliferadas em e por instituições de ensino superior - podem ser neutralizadas e porque promover a justiça epistêmica exige o reposicionamento das universidades como uma contra muitas em um ecossistema mais amplo de pedagogias urbanas, em diálogo aberto e produtivo com novas formas institucionais, definidas por Boaventura de Sousa Santos como a 'pluriversidade' e a 'subversidade'.

Palavras-chave: Injustiça Epistêmica. Planejamento Urbano. Pedagogia Crítica. Pluriversidade e Subversidade. Movimentos Sociais.

ABSTRACT - One Amongst Many: higher education institutions in an ecosystem of urban pedagogies. This paper explores how and why pedagogues within universities can and need to work as 'one amongst many' to advance critical pedagogies for urban equality. The discussion draws on two contrasting experiences: the networked schools of the Habitat International Coalition in Latin America (HIC-AL) - a coalition of civil society organizations, social movements and universities working in defense of habitat-related human rights - and the co-learning processes with housing rights activists activated by the Indian Institute for Human Settlements (IIHS) - a national education institution com- 
mitted to the equitable, sustainable and efficient transformation of Indian settlements. Both experiences place emphasis on crafting critical pedagogies that seek to fundamentally disrupt, re-frame and re-position institutional relations of knowledges and learning practices, while advancing capacities for transformative urban change. The analysis demonstrates how epistemic injustices - often proliferated in and by higher education institutions - can be counteracted, and why fostering epistemic justice requires re-positioning universities as one amongst many in a wider ecosystem of urban pedagogies, in open and productive dialogue with new institutional forms that Boaventura de Sousa Santos defines as the 'pluriversity' and the 'subversity'.

Keywords: Epistemic Injustice. Urban Planning. Critical Pedagogy. Pluriversity and Subversity. Social Movements.

\section{Introdução}

De maneira geral, as instituições de ensino superior (IESs) são consideradas como atores fundamentais para responder aos atuais desafios de crescente urbanização e desigualdade no Sul global, uma aspiração baseada na função da universidade como produtora e mediadora de conhecimento para o bem público, se esforçando por um impacto no mundo real e pela excelência acadêmica (Addie, 2019; Swartz et al., 2019). No campo da educação em planejamento urbano, os arranjos institucionais de docência, prática e pesquisa se reúnem em diferentes constelações, como estúdios colaborativos e alianças de aprendizagem, em que os educandos adquirem experiência em planejamento na medida em que coproduzem conhecimento com comunidades de prática consolidada. Conceitualmente, muitos destes esforços arraigados na teoria urbana sustentam o potencial de contribuição para uma "virada urbana" em pedagogia crítica, um campo que define a arquitetura da aprendizagem como uma prática política e moral (Giroux, 2011), estimulando o pensamento crítico e a prática reflexiva sobre como as cidades são lidas, compreendidas, habitadas e formatadas (McFarlane, 2011). Entretanto, na prática pedagógica, compreensões isoladas de disciplinas, instituições e profissões, bem como as hierarquias em processos de criação da cidade que representam, resultam em significativas tensões que inibem a aprendizagem urbana crítica e tendem a reforçar ou exacerbar as epistemologias ocidentais, coloniais e excludentes hegemônicas (Watson; Odendaal, 2013; Wesely; Allen, 2019).

Este artigo aborda essas tensões com base em três campos de pesquisa interconectados: primeiro, as injustiças epistêmicas no contexto do deslocamento do lócus de urbanização para o Sul global e a multiplicidade de saberes que são ativados e mobilizados em processos de desenvolvimento urbano informais e populares; em segundo lugar, as funções das IESs no Sul global ao coproduzirem e mediarem saberes e alternativas para pluralizar e desacomodar o imaginário da universidade; e, terceiro, a contribuição das pedagogias críticas para a transformação urbana em termos destas iniciativas. Estes três campos são trazidos à conversa por meio de duas experiências distintas: as escolas em rede da Habitat International Coalition América Latina (HIC-AL) e as 
oficinas de coaprendizagem com ativistas pelos direitos à moradia no Indian Institute for Human Settlements.

A Habitat International Coalition (HIC) é uma coalizão global que reúne mais de 350 organizações da sociedade civil, instituições acadêmicas e de pesquisa, movimentos sociais e ONGs trabalhando coletivamente para a efetivação dos direitos humanos relacionados à moradia. A coalizão tem uma estrutura operacional ágil e é regida por seus integrantes e suas estratégias pedagógicas e de proteção. Fundada em 1976, desde então a HIC tem sido um ativo agente desde o nível local até o internacional ao tornar visível, produzir e defender os direitos à moradia para todos (Habitat International Coalition, 2018). Uma característica

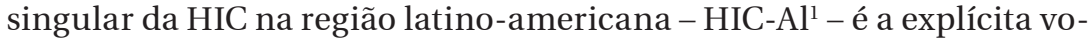
cação para o trabalho em múltiplas escolas em rede, apesar de autônomas (Wesely et al., 2021). Estas escolas constituem um guarda-chuva para uma gama de experiências de aprendizagem realizadas por indivíduos e grupos de integrantes, como escolas de cooperativismo, escolas de líderes comunitários e escolas de cidadania, entre outras. As escolas da HIC-AL funcionam em rede e são mantidas unidas pelos princípios e práticas com os quais a Coalizão se compromete (Habitat International Coalition, 2018; Wesely et al., 2021).

O Indian Institute for Human Settlements (IHHS²) é uma instituição de ensino nacional comprometida em responder aos desafios da urbanização na Îndia e promover transformações urbanas sustentáveis em grande escala. Fundado em 2008 com contribuições intelectuais e financeiras de um grupo de eminentes hindus de todos os estratos sociais, a visão do IIHS gira em torno da formação de uma nova geração de profissionais de urbanismo com a oferta de um conjunto de cursos de graduação novos em Prática Urbana, bem como da realização de pesquisas e da prática interdisciplinar para ajudar a construir novos conhecimentos. Atualmente, o instituto está estruturado em torno de quatro programas centrais: Acadêmico, Pesquisa, Prática e Capacitação. A interdisciplinaridade está no centro de todos os programas do IIHS, institucionalmente orientada para romper com as limitações do modelo como um-departamento-uma-disciplina na universidade o sistema de educação prevalente na Índia - com o propósito de criar novas culturas de ensino, pesquisa e prática. Neste artigo, discutimos uma das experiências pedagógicas do IIHS: seu envolvimento continuado com ativistas pelos direitos à moradia que trabalham em diferentes partes do país.

Este artigo utiliza a justaposição de Caldeira (2017) de experiências distintas como um método para questionar como as experiências pedagógicas da HIC-AL e do IIHS desafiam as tensões epistêmicas e institucionais em seus respectivos contextos. Ao responder, nos concentramos especificamente na incorporação, nos potenciais e nos desafios contextuais destas experiências para romper, reformular e reposicionar as articulações institucionais dos múltiplos saberes e práticas de aprendizagem que fazem o 'urbano'. 
A análise da HIC-AL está baseada em uma revisão da literatura que sintetizou um grande número de relatórios publicados e internos. Empiricamente, está baseada em um trabalho de campo remoto e presencial conduzido a partir de junho de 2019, incluindo conversas em profundidade com 21 integrantes, coordenadores e afiliados da HIC-AL em nove países e, em alguns casos, observações participantes das escolas. Neste artigo, analisamos especificamente aquelas escolas que são administradas por, ou em colaboração com, universidades integrantes da HIC-AL. A análise do IIHS está embasada na participação das autoras no projeto e oferta destas oficinas de coaprendizagem. Além de relatos e reflexões pessoais, está embasada em documentação do processo, registros de oficinas, testemunhos em vídeo, reflexões verbais de ativistas, além de discussões com outros pesquisadores diretamente envolvidos nestas oficinas e/ou outras experiências pedagógicas no IIHS. Todas as autoras são pesquisadoras no programa Knowledge in Action for Urban Equality [Conhecimento em Ação para a Igualdade Urbana], que oferece uma plataforma para colocar estas duas experiências em uma conversa comparativa.

As seções a seguir esboçam os principais debates em e entre as três áreas de investigação acima mencionadas: injustiça epistêmica em urbanismo e planejamento urbano no Sul global, funções alternativas de instituições de ensino superior e pedagogias críticas para a transformação urbana.

\section{Injustiça epistêmica no Sul global urbano}

Há muito tempo o urbanismo e o planejamento urbano no Sul global têm sido sítios de injustiça epistêmica (Fricker, 2007). Isso se manifesta, por exemplo, na marginalização estrutural das populações urbanas informais e no déficit de credibilidade em termos de sua capacidade como conhecedoras de sua própria realidade (justiça testemunhal), bem como na inabilidade social e institucional para responder de maneira eficaz às suas experiências (injustiça hermenêutica). Em parte, isso foi atribuído à dominância das culturas de planejamento e da educação profissional em planejamento em contextos do Sul, muito arraigados em legados coloniais (UN-Habitat, 2009; Watson, 2011). Agravadas pelo deslocamento no lócus de urbanização para o Sul global, a relevância e a absoluta representatividade das teorias de planejamento urbano dominantes sofreu um escrutínio intensificado ao longo da última década. Houve diversos chamados pela teorização a partir do Sul e da prática (Parnell; Pieterse; Watson, 2009; Parnell; Robinson, 2012; Watson, 2009) e para decolonizar a educação de futuros profissionais de urbanismo (Watson; Odendaal, 2013). Ao defender a expansão de um vocabulário de prática urbana do Sul, Bhan (2019) discute que, oriundos do ensino disciplinar desarraigado, muitas vezes os profissionais de urbanismo lutam para articular o conhecimento prevalente em suas formas de prática específicas. Além disso, defende que a prática urbana em si é definida e interpretada de maneira demasiadamente estreita, 
reforçando a hierarquia e a segmentação dos profissionais e seus modos de prática. Isto, sugere ele, resulta em cânones disciplinares que dominam a prática profissional e que carecem de coisas conhecidas graças a diferentes modos de prática (Bhan, 2019).

Juntamente com os chamados para descentrar a teoria urbana, também tem havido ênfase na coprodução de conhecimento, que dá protagonismo à necessidade de reconhecer múltiplos detentores de conhecimento em suas capacidades e pautas para articular, negociar e coproduzir os modos de compreender e atuar sobre uma transformação urbana que verdadeiramente promova pautas urbanas mais inclusivas. Entretanto, Mitlin et al. (2019) discutem que a coprodução enfrenta desafios significativos, particularmente ao abordar relações de poder e status desiguais entre acadêmicos e não acadêmicos, sugerindo que muitas vezes os acadêmicos ainda são insuficientemente autocríticos a respeito da dinâmica do poder; com isso, reforçam involuntariamente as injustiças testemunhais e hermenêuticas. $\mathrm{O}$ que requer maior elaboração neste debate é uma discussão sobre as pedagogias de sustentação empregadas para coaprender a cidade, conforme foi destacado por Allen, Lambert e Yap (2018) e McFarlane (2018). Além de questões familiares como 'o que conta como conhecimento?' ou 'de quem é o conhecimento que conta?', McFarlane (2018, p. 323-324) sugere que os pesquisadores e planejadores urbanos precisam interrogar "com quem, com o quê, para qual finalidade e sob quais condições de poder e inclusão [eles] aprendem”. Allen, Lambert e Yap (2018) discutem que também precisamos responder criticamente a perguntas sobre 'onde', 'como' e 'por qual motivo' coaprendemos a cidade. A este respeito, o conceito de injustiça epistêmica constitui uma útil lente para destacar aspectos fundamentais de poder e ética em pedagogia urbana no Sul global (Allen; Wesely, 2020; Boni; Velasco, 2019), forçando-nos a pensar criticamente sobre como e de quem é o conhecimento produzido, traduzido, compartilhado e apropriado em processos de aprendizagem e com quais resultados.

Ao examinar como as injustiças epistêmicas podem ser enfrentadas ou reproduzidas na teoria, na prática e na pedagogia urbana do Sul, a discussão a seguir revela as funções que as universidades desempenham como um dos muitos produtores e mediadores de conhecimento e seu potencial para cogerar e transformar práticas urbanas de aprendizagem.

\section{Além do Iluminismo: os papéis alternativos das instituições de ensino superior}

Durante o último século, as disciplinas relacionadas ao urbano foram sendo institucionalizadas nas universidades em resposta aos crescentes níveis de urbanização e demandas associadas para profissionalizar o setor; isso se manifesta na proliferação de cursos de planejamento urbano, design urbano e estudos urbanos, entre outros (Davoudi; Pendlebury, 2010). Com a intenção de facilitar a produção e 
a mediação de conhecimento e construir capacidades para dar forma a um mundo cada vez mais urbano, a universidade se embasa em diversas funções, como ensino ou formação, pesquisa, prática, consultoria, defesa e extensão comunitária. Como um sítio de ensino superior, a universidade detém 'funcionalidades institucionais' para contestar as desigualdades por meio de valores articulados, um portfólio de práticas e espaços de oportunidade (Frediani et al., 2020). Entretanto, clamores antigos para decolonizar a universidade destacam como ela continua sendo um sítio de poder arraigado que ainda hoje reforça as epistemologias ocidentais e coloniais dominantes. Em outras palavras, a universidade ativamente cria 'outros' e promove a reprodução de injustiças epistêmicas por meio de três projetos paralelos, porém separados (Boidin; Cohen; Grosfoguel, 2012; Santos, 2018). Primeiro, através da criação de estruturas disciplinares isoladas com hierarquias racionais, científicas ou tecnológicas. Segundo, ao não reconhecer e neutralizar o que é sistemicamente inaudito através de estruturas coloniais ou patriarcais opressoras. Em terceiro lugar, por meio da relação da universidade com o capitalismo contemporâneo como uma pedagogia e, por conseguinte, como uma entidade na economia política que valoriza o conhecimento reconhecido pelo 'mercado' (Giroux, 2003; Santos, 2018).

Ao promover modos alternativos de pensamento e de prática, Santos (2018) convoca para uma atenção mais próxima e crítica às 'epistemologias do Sul' coletivas e performativas, situadas na "produção e validação de saberes ancorados em experiências de resistência" (Santos, 2018, p. 4). Ele questiona o modelo kantiano-humboldtiano eurocêntrico da universidade que valoriza uma forma singular de conhecimento e sugere o conceito de uma universidade 'polifônica'. Como o termo sugere, a universidade polifônica reconhece uma 'ecologia de saberes' e “exercita seu compromisso de uma maneira pluralista, não apenas em termos de conteúdos substantivos, mas também em termos institucionais e organizacionais" (Santos, 2018, p. 277). Além disso, Santos argumenta que a universidade polifônica pode ser efetivada de duas maneiras: a 'pluriversidade' e a 'subversidade' (Santos, 2018). A pluriversidade está situada nas estruturas institucionais existentes, com possibilidades de reformar e decolonizar a instituição da universidade a partir de dentro. As discussões sobre a pluriversidade incluem as interconexões através de suas várias funções institucionais de ensino, pesquisa e prática, e um rol de métodos que reconhecem saberes e posicionamentos diversos, com devolução em espaços institucionais (Martinez-Vargas, 2020). A subversidade, por outro lado, opera como um espaço pedagógico fora dos limites institucionais convencionais, por exemplo através de movimentos sociais, tendo como premissa uma "pedagogia do conflito" (Santos, 2018, p. 281). A subversidade situa a universidade como um de diversos atores e um entre diversos sítios de poder, e a reconhece por seu 'uso contra-hegemônico' - subversivamente intervindo em suas ações convencionais como mediadora e produtora de conhecimento (Santos, 2018). 
Os debates e a imagem mental da universidade polifônica falam ao reconhecimento de saberes diversos, defendendo a pluralização dos sítios onde o conhecimento é criado, articulado, revelado e incorporado. Conectando este argumento com o domínio urbano, isso ressoa com as discussões anteriores sobre 'aprender a cidade' (McFarlane, 2011), coprodução de conhecimento na prática, pesquisa e pedagogia urbana (Mitlin, 2008; Mitlin et al., 2019), coaprendizagem como uma prática crítica (Allen; Lambert; Yap, 2018) e a relação de universidades e ativistas como uma prática urbana (Frediani et al., 2020).

\section{Pedagogias críticas para a transformação urbana}

O campo da pedagogia crítica, como uma prática explicitamente política e moral (Giroux, 2011), tem sido um espaço decisivo pelo qual as instituições de ensino superior, os movimentos sociais e outros atores urbanos provocam a consciência crítica e respondem às injustiças epistêmicas em urbanismo no Sul global. Embora a Pedagogia do Oprimido de Paulo Freire (1970) tenha sido desenvolvida no contexto das lutas camponesas e da teologia da libertação no Brasil, foi desafiada a se abrir para diferentes geografias e lutas contemporâneas (Tarlau, 2014). Diversos estudiosos, por exemplo, exploraram como a pedagogia crítica e a educação cívica estimularam o agenciamento de educandos no contexto de bairros urbanos desfavorecidos ou grupos sociais urbanos dos Estados Unidos (Kirk et al., 2007, Zápoto ná, 2012). No ensino superior, cursos de planejamento urbano progressista no Sul e no Norte global têm se engajado em experiências de aprendizagem consolidada, seguindo abordagens problematizadoras como estúdios, engajamento comunitário e prática para refletir e agir criticamente sobre desafios urbanos específicos ao contexto (Allen; Lambert; Yap, 2018; Watson; Odendaal, 2013).

Além disso, as pedagogias críticas têm se expandido rumo à intersecção ao invés de uma única compreensão de classe social de educandos oprimidos (Lynn, 2004). Estudiosos negros, feministas e indígenas têm noções pluralizadas de oprimido em relação à dominação estrutural e patriarcal (Nesga, 1993; hooks, 2003). Isto ressoa com o trabalho de muitos estudiosos na América Latina (ver, por exemplo, Marzioni, 2012 e Ortiz Ocaña; Arias López, 2018), onde, além disso, a pedagogia crítica tem uma longa história de apoio à articulação de lutas populares e desenvolvimento do agenciamento de movimentos sociais e de populações urbanas em geral marginalizadas que lutam por seus direitos à moradia e à cidade (Kane, 2012).

A discussão que segue busca ilustrar e comparar as experiências da HIC-AL e do IIHS para elucidar como suas pedagogias críticas para transformação urbana rompem, reformulam e reposicionam as relações institucionais de saberes e práticas de aprendizagem, contribuindo para promover as ideias e as práticas avançadas da pluriversidade $\mathrm{e}$ da subversidade. 


\section{Escolas em rede da $\mathrm{HIC}-\mathrm{AL}$}

As escolas da HIC-AL são administradas com um elevado grau de autonomia por seus integrantes, amigos e aliados, pois a Coalizão prioriza o protagonismo e o fortalecimento do agenciamento das forças sociais apoiadas por seus integrantes. As escolas são caracterizadas por uma alta heterogeneidade em termos de educandos e educadores (líderes comunitários, integrantes cooperativistas, jovens, grupos de mulheres e autoridades do governo local, entre outros), bem como um compromisso com a aprendizagem horizontal, contra-hegemônica. As perspectivas pluralistas sobre (co)produção de conhecimento são centrais para estas experiências pedagógicas, muitas vezes envolvendo instituições e docentes de ensino superior como um entre muitos atores. Além disso - em alinhamento com a noção de 'movimento como uma escola' de Freire (1991, apud Kane, 2012) - as escolas da HIC-AL não são uma instituição, mas sim um conjunto de práticas pedagógicas altamente diversificadas que atribuem igual valor à promoção de maneiras críticas de fazer e de saber (saberes y haceres).

Estas heterogeneidades significam que as escolas da HIC-AL não existem em um espaço institucional único e definido, como a universidade, mas permeiam múltiplos sítios de aprendizagem, incluindo bairros, plataformas on line, centros comunitários e, em alguns casos, também sítios de educação formal. Além disso, as escolas não seguem um currículo pré-definido, aceito de comum acordo. Ao contrário, o currículo é aberto, muitas vezes desenvolvido coletivamente 'em movimento', orientado pelos princípios da Coalizão, e que responde, fundamentalmente, aos desafios políticos, econômicos, sociais, culturais e ecológicos específicos enfrentados por suas escolas.

No entanto, o que a maioria das escolas - suas pedagogias e justificativas - tem em comum é sua capacidade de resposta a tensões epistêmicas e institucionais por meio de estratégias pedagógicas que são analisadas por meio de experiências concretas nos parágrafos a seguir.

\section{Fortalecendo o reconhecimento de práticas de moradia popular no ensino superior}

O Taller de Vivienda (Oficina de Moradia) na Universidade Autônoma Metropolitana-Xochimilco (UAM-X), instituição pública mexicana, é um exemplo ilustrativo de uma abordagem integrada e holística à pesquisa, docência e engajamento público para promover direitos relacionados à moradia. Situando-se junto à tensão entre as práticas de planejamento profissional e as práticas populares de moradia que são a modalidade dominante de desenvolvimento urbano e rural no México, seu objetivo fundamental é "formar profissionais que apoiem processos para o enfrentamento de problemas socialmente relevantes, [através de um sistema de ensino de] aprendizagem por meio da resolução" (Entrevista com acadêmico, 11 de dezembro de 2019). 
Desde sua fundação em 1974, a UAM-X adotou e desenvolveu ainda mais o assim-chamado 'Sistema Modular' como uma estratégia contra-hegemônica às estruturas organizacionais e pedagógicas isoladas e disciplinares prevalentes em universidades e às tensões epistêmicas provocadas por elas - por exemplo, entre saberes locais e acadêmicos e entre ciências sociais e naturais, entre outras. O Sistema Modular é organizado em torno de departamentos e grupos de pesquisa multidisciplinares ao invés de faculdades por disciplina, aplicando uma pedagogia baseada em pesquisa para identificar, reformular e potencialmente resolver problemas relevantes na sociedade ao longo de todo o currículo (Arbesú García; Ortega Esparza, 2006).

O Taller de Vivienda surgiu depois do terremoto de 1985 no México, inicialmente para investigar e responder às demandas habitacionais imediatas e, mais tarde, para informar a reconstrução justa em longo prazo dos bairros populares afetados. Sua pedagogia problematizadora e baseada em pesquisa objetiva preencher a lacuna entre o ensino acadêmico e as estruturas isoladas de prática ao provocar o pensamento e a ação por meio de desafios urbano-territoriais que demandam respostas inter e transdisciplinares (Entrevista com acadêmico, 11 de dezembro de 2019). Isto significa que estudantes e educadores de diferentes disciplinas trabalham junto com as populações locais afetadas para resolver os desafios específicos de moradia com base nas vivências deles. Isso varia desde a ventilação interna insuficiente até a falta de espaço público adequado; assim, exige respostas das perspectivas da saúde, da arquitetura e design, do meio ambiente, das políticas públicas e outras. Deste modo, esta pedagogia se recusa a organizar a educação em temas ou matérias e rompe com a suposta linearidade da aprendizagem da teoria rumo à práxis. Por meio de reflexões individuais e coletivas iterativas durante o processo, explicita o posicionamento dos estudantes, moradores, educadores e outros na economia política de saberes que operam ativamente em torno das questões habitacionais (Arbesú García; Ortega Esparza, 2006). Outro elemento importante é a noção de pesquisador/a-docente, portanto, educador/a-pesquisador/a como uma função intrinsecamente vinculada. Ensinar e aprender sempre se beneficiam e contribuem para projetos de pesquisa específicos, e muitas vezes os estudantes e os egressos fazem a transição para projetos de pesquisa depois de participarem das oficinas iniciais.

O Taller de Vivienda tem um longo engajamento com e em bairros populares, onde os educandos das IESs coproduzem caminhos para soluções habitacionais em parceria com os moradores locais. Diferentemente de outras experiências orientadas pela universidade, o envolvimento crítico com a prática ocorre desde o começo dos cursos; com isso, apoia os educandos de maneira continuada na construção de habilidades e capacidades profissionais para se tornarem um dos muitos atores no planejamento de desenvolvimento. Ao mesmo tempo, saberes e práticas populares relacionados aos direitos à moradia se tornam visíveis e validados de diferentes maneiras no espaço formal da universidade. Isto inclui o conteúdo do currículo, as justaposições físicas que 
trazem a sala de aula para a comunidade e vice-versa, assim como a política da universidade de aumentar o acesso à educação superior para estudantes de bairros populares. Isto é muito importante, pois alimenta a capacidade de integrantes da comunidade de transformar sua própria realidade ao oferecer um estímulo para que os estudantes aprendam uns com os outros e reconheçam os saberes que trazem para um espaço de aprendizagem em comum (Entrevista com acadêmico, 11 de dezembro de 2019).

\section{Promovendo saberes pluralistas e perspectivas intersetoriais}

Outra tensão epistêmica importante é enfrentada ao dar visibilidade, valorizar e fazer a intersecção com saberes indígenas e feministas em torno de questões relacionadas à moradia, tanto por aqueles que extraem seu conhecimento da experiência direta como aqueles que estão situados em instituições formais. Diversas escolas relataram o déficit simultâneo de credibilidade devido ao conhecimento experiencial das comunidades e aos excessos epistêmicos de conhecimento institucional ou profissional que exacerbam as injustiças testemunhais, manifestando-se, por exemplo, através da marca de políticas de moradia neoliberais nos imaginários de moradias populares. Na pequena cidade de San Martín de los Andes, Argentina, começou em 2011 um processo de desenho participativo com a ONG Vecinos sin Techos e a Comunidade Indígena Curruhuinca Mapuche, facilitado pela Universidade Nacional de Córdoba e compreendendo 42 oficinas sobre temas como autonomia de energia e restituição da terra. Sua abordagem pedagógica abordava explicitamente a estigmatização profundamente arraigada da comunidade indígena e suas manifestações socioespaciais, procurando alimentar perspectivas pluralistas e sinérgicas através dos assim-chamados espacios de interaprendizaje cultural [espaços de interaprendizagem cultural] (Entrevista com acadêmico, 29 de novembro de 2019).

Esta pedagogia está apoiada sobre a justaposição e a articulação explícitas de saberes técnicos e locais profissionais com a intenção de interfertilizar ideias e práticas. Em outras palavras, identificar e validar coletivamente os saberes existentes da comunidade indígena, de moradores de baixa renda e de profissionais que estejam contribuindo para diferentes aspectos do habitar um bairro, e procurar combinar estas diferentes maneiras de saber e fazer (saberes y haceres) para gerar soluções e alavancar a promoção política para pressionar por questões de moradia e outros mais estruturais. Neste processo, o uso de métodos participativos como exercícios de dramatização e de visualização, promoveu a capacitação para o pensamento crítico e a prática ao alimentar imaginários de futuras maneiras de convivência, ao também colocar os educandos no lugar dos outros (Entrevista com acadêmico, 29 de novembro de 2019). Este processo participativo bem documentado e amplamente reconhecido originou uma compreensão interseccional de identidades e para a formação do assim-chamado Barrio Intercultural SustentableComunidad del Cambio [Bairro Intercultural Sustentável-Comunidade 
de Mudança], que fundamentalmente reformatou as hierarquias em saberes e prática. A experiência foi consolidada conceitual, metodologica e institucionalmente em um curso de graduação chamado Diseño Participativo Sustentable del Hábitat [Desenho Participativo Sustentável de Moradias], coordenado pela Universidade Nacional em Córdoba, Argentina, e pela Universidade Autônoma Nacional do México (Enet; Romero, 2019). Neste programa, os moradores do Barrio Intercultural fazem parte da equipe de educadores - dialogando e analisando criticamente suas experiências para promover a aprendizagem e o agenciamento coletivo entre lutas indígenas, interculturais e por moradia na América Latina.

\section{Abrindo espaços para a pluriversidade e a subversidade}

Os parágrafos anteriores mostraram diferentes vias pedagógicas para abrir espaço para a pluriversidade e a subversidade ao trazer $s a$ beres y haceres da produção social e gestão de moradia para as universidades e ao expor os educandos a lutas populares por moradia que geralmente não fazem parte dos currículos formais de profissões voltadas ao ambiente construído. Ao mesmo tempo, outras escolas da HIC-AL contestam modelos de ensino superior neoliberais e pedagogias capitalistas ao desenvolver outros modelos de subversidade, como o Centro Educativo Integral Autogestionário (CEIA), fundado pelo Movimento Argentino de Ocupantes e Inquilinos (MOI), ou a escola de advogados comunitários da Associação Civil para Igualdade e Justiça (ACIJ).

A primeira experiência se refere a uma instituição educacional autônoma administrada por cooperativas, que inclui um jardim, dois bacharelados populares, uma biblioteca e um centro de treinamento (Habitat International Coalition, 2018; Rodríguez, 2013). A segunda compreende um programa com três meses de duração para homens e mulheres que vivem em assentamentos informais. São discutidos e desenvolvidos conceitos e teorias embasadas em direitos (como o direito à cidade e direitos humanos), assim como atividades práticas (formulação de demandas por serviços públicos às autoridades e de campanhas), por meio de uma série de oficinas (Representante de ONG, comunicação pessoal, 5 de junho de 2021). Capacitar advogados comunitários para participarem de processos de desenvolvimento urbano para reivindicar seus direitos representa uma ruptura gritante com o imaginário prevalente do advogado profissional, formado pela universidade. É importante destacar que o programa foi desenvolvido em colaboração com, e funciona fisicamente, na Faculdade de Direito da Universidade de Buenos Aires. O local físico de aprendizagem é notável e contra-hegemônico, pois a Faculdade fica espacialmente perto e com vista para a Villa Retiro, um bairro cujos representantes comunitários obtiveram acesso ao campus da IES pela primeira vez graças à escola, apesar do flagrante contraste socioeconômico e do pouco contato com ela. Além disso, os advogados profissionalmente treinados pela Faculdade são apenas um entre os muitos educadores que lecionam neste curso na universidade, 
Um Entre Muitos

juntamente com integrantes locais de uma ONG e da comunidade (Representante de ONG, comunicação pessoal, 5 junho 2021).

\section{Estratégias e táticas pedagógicas para contestar injustiças testemunhais e hermenêuticas}

As pedagogias da HIC-AL contêm diversas vias para abordar as injustiças testemunhais. Muitas escolas partem das vivências e problemas das pessoas associados a suas moradias em pequena escala, porém em sua complexidade total. Por exemplo, os saberes experienciais baseados na organização coletiva do bairro, compreender processos burocráticos, direitos legais e mecanismos para enfrentar despejos ou experiência das mulheres com assédio em espaços públicos são, entre outros, reconhecidos e avaliados em seu impacto coletivo. Ao discutir, refletir e validar estas experiências, as escolas forjam uma relação dialógica mais do que subordinar experiências locais a outras formas de conhecimento profissional. Além disso, as escolas da HIC-AL operam sobre uma base de aprendizagem a partir de haceres y saberes, significando que as diferentes maneiras de fazer estão inextricavelmente ligadas às maneiras de saber. Consequentemente, a ação não se transforma em um adendo ou um produto colateral da aprendizagem, mas segue uma abordagem relacional e dialógica freireana. Por exemplo, a segurança da posse como uma proposta teórico-conceitual está vinculada desde o princípio a ações políticas individuais e coletivas como resistência a despejos, fortalecimento de modelos de moradia cooperativos comunitários fora do mercado, construção de prédios com técnicas artesanais que sejam mais resistentes a eventos climáticos extremos e aumento da segurança nos bairros especialmente para mulheres, meninas e comunidades LGBTQ. Pode-se discutir que esta abordagem pedagógica relacional e ativadora de agenciamento gera capacidades para contestar a asfixia testemunhal - a decisão de falantes (oprimidos) de continuarem em silêncio ou adaptarem seu testemunho por medo de um público que não esteja verdadeiramente escutando e sim propenso a manipular ou negar este testemunho (Dotson, 2011).

A meta explícita de muitas escolas da HIC de pluralizar saberes e identidades, como no caso do Barrio Intercultural, provoca ainda mais a reformulação do posicionamento e de responsabilidades de conhecedores diferentes e seu agenciamento individual e coletivo para dar forma à transformação urbana. Estimuladas por métodos como dramatização e cartografia crítica, as escolas da HIC-AL apoiam a mudança em relações de dominância e hierarquias tradicionais que muitas vezes estão arraigadas na relação entre práticas de moradia popular e saberes profissionais, provocando uma articulação e um testemunho com mais nuances e horizontal e entre os movimentos sociais e os profissionais, inclusive os acadêmicos.

A natureza profundamente estrutural das injustiças hermenêuticas dificulta sua identificação nas experiências específicas de escolas individuais. Entretanto, em nível de rede, seu vocabulário comparti- 
lhado de produção social de moradia e direitos humanos - o que inclui noções comuns fundamentais como 'autogestión', direitos relacionados à moradia e cooperativismo - proporciona um veículo importante para tornar as experiências populares comunicáveis, compreensíveis e compreendidas. Por exemplo, desde sua origem para apoiar os esforços de reconstrução após o terremoto de 1985, o Taller de Vivienda da UAM-X reuniu estudantes e moradores de bairros populares para trabalharem coletivamente em questões de moradia e, desse modo, institucionalizou os saberes populares e as lutas por território através e além do currículo da universidade. Esta abordagem à 'formación' como educação holística de profissionais de arquitetura e planejamento urbano contribui para a resistência hermenêutica contra a mercantilização e a comodificação da terra e da moradia ao expandir e profissionalizar um vocabulário metodológico, conceitual e prático em torno de alternativas de moradia popular e coletiva que se contraponha aos discursos de desenvolvimento urbano excludente e elitista dominantes.

\section{Processos iterativos de reflexão e consolidação da aprendizagem em rede}

Muitas escolas da HIC-AL operaram durante décadas sob contextos políticos desafiadores, como transições de ditaduras para a democracia, alterações constitucionais ou modificações de governança para descentralização e autonomia municipal. O amplo alcance geográfico, a alta diversidade e a longevidade das escolas da HIC-AL resultam em uma rica oportunidade para aprendizagem translocal e intergeracional. Hermeneuticamente, tem potencial para uma atualização iterativa e contínua de um vocabulário compartilhado em torno da 'produção social da moradia' e dos direitos relacionados à moradia que sejam sensíveis a diferentes lutas contextuais travadas por integrantes da HICAL. Além disso, a HIC-AL está continuamente consolidando e refletindo sobre seu repertório de pedagogias, com a possibilidade de criar mais espaços de coaprendizagem translocal. Com este objetivo, a HIC-AL fundou um Grupo de Trabalho em Capacitação que desde 2013 reúne 61 educadores de sete países da América Latina, trabalhando especificamente na síntese e na tradução de experiências pedagógicas de movimentos sociais e organizações da sociedade civil em currículos formais. Ao longo do tempo, este grupo criou o curso acima mencionado na Universidade Nacional Autônoma do México com base na experiência de desenho participativo do projeto de San Martín de los Andes.

As recentes transformações para a aprendizagem on line se expandiram devido à pandemia da COVID-19, abrindo outras possibilidades para intercâmbios virtuais de conhecimento, em que as experiências de lutas coletivas são compartilhadas na região com educandos de diferentes origens institucionais e organizacionais. Uma iniciativa da HIC em andamento para desenvolver 'espaços de coaprendizagem' na América Latina, África e regiões do Oriente Médio e Norte da África procura dar continuidade a esta consolidação e expansão da aprendizagem 
Um Entre Muitos

em rede dentro e além da HIC-AL para promover a articulação de pedagogias críticas com integrantes, amigos e aliados da HIC no mundo.

\section{Coaprendizagem com ativistas pelos direitos à moradia na Índia}

Ao longo dos anos, o IIHS conduziu diversos cursos de longa e média duração. Aqui enfatizamos nosso envolvimento continuado com ativistas pelos direitos à moradia que trabalham em diferentes regiões do país. Esta experiência está integrada ao programa de capacitação do IIHS direcionada a um largo espectro de profissionais de urbanismo incluindo gestores, representantes eleitos, engenheiros e planejadores municipais, movimentos populares e ativistas. A colaboração teve um modesto começo em 2015 com a realização de uma oficina de dois dias em planejamento urbano para ativistas na Índia; desde então, evoluiu para uma experiência pedagógica continuada em coaprendizagem. Operacionalizada fundamentalmente por meio de oficinas, este engajamento colaborativo é centrado no educando e com abordagem dialógica e incremental. Na época da elaboração deste artigo, foi realizado um total de dez oficinas durante cinco anos em quatro cidades da Índia, com a participação de aproximadamente oitenta ativistas e agentes comunitários, oito estudantes inscritos como bolsistas por nove meses no IIHS, e quinze acadêmicos e pesquisadores do IIHS

\section{A necessidade de se envolver com educação em planejamento}

Muitos estudiosos têm discutido que a educação em planejamento e, consequentemente, as práticas de planejamento na India produzem espaços urbanos injustos e perpetuam a desigualdade e a exclusão nas cidades (Mahadevia; Joshi, 2009; Mahadevia; Bhatia, 2018). As realidades socioeconômicas de grandes parcelas da sociedade hindu urbana não são reconhecidas nem abordadas, embora frequentemente muitas sejam marginalizadas pelo uso de instrumentos de planejamento coloniais desatualizados. Neste contexto, esta experiência objetiva se envolver com algumas das tensões da educação em planejamento na Índia que, em geral, continuam sendo excludentes e exclusivas.

Enquanto, no papel, o planejamento continua sendo um processo participativo na India, muito poucas pessoas têm acesso ao conhecimento e ao entendimento de processos oficiais de planejamento. A linguagem 'profissional' ou 'especializada' dos planos oficiais impede que grupos de cidadãos e ativistas se engajem de maneira significativa nestes processos e, com isso, determina quem, na prática, se engaja em modificações urbanas transformadoras por meio de seus saberes tácitos e práticas cotidianas, inclusive ativismo, mobilização social e promoção. Enquanto o conhecimento técnico em planejamento urbano não alcança os cidadãos, as implicações em campo dos instrumentos de planejamento o fazem. No crescente foco sobre a urbanização na Índia desde a virada do século, quando os projetos de desenvolvimento 
e despejos começaram a citar estes planos, os ativistas pelos direitos à moradia reconheceram esta falta de compreensão como uma luta. A demanda por conhecer a justificativa dos planos diretores surgiu em 2015 por parte de um coletivo de ativistas que trabalham com direitos à terra e à moradia no país, que tinham uma compreensão em profundidade de como os processos de planejamento oficiais e os resultados do trabalho seriam uma útil aquisição para sua caixa de ferramentas. No fim de nossa primeira oficina, um dos participantes enfatizou:

"Vamos às ruas, barganhamos e lutamos [...] fizemos marchas silenciosas, fizemos de tudo. Mas como fazer para que o governo nos escute e trabalhe em colaboração? Hoje retorno com uma ferramenta [Plano Diretor]" (Depoimento em vídeo, 7 de novembro de 2015).

Por meio destes engajamentos, não pretendemos sugerir que o conhecimento e as práticas formais de planejamento tenham mais peso e importância do que o conhecimento vivido e as práticas cotidianas. Na realidade, a maioria das cidades na Índia não se parece com seus planos; entretanto, conforme foi discutido por Bhan (2013, p. 69), “[...] os profissionais de urbanismo em uma cidade como Deli não têm nenhuma opção a não ser se envolver com o plano justamente devido à contínua relevância de seu fracasso". Projetadas em resposta a injustiças hermenêuticas, a intenção das oficinas do IIHS é fortalecer e expandir o conhecimento e o vocabulário dos ativistas para contestar injustiças epistêmicas em planejamento urbano. É importante destacar que o vocabulário técnico em si não assegura que o testemunho seja escutado; porém, permite momentos em que pressupostos desacomodem as pessoas como conhecedores e, assim, manejem o poder. Em uma discussão recente, um ativista participante, oriundo de Indore, compartilhou a experiência de como uma comunidade defendeu com sucesso seu direito de ficar ao citar seu compromisso com as cláusulas sobre o uso da terra no Plano Diretor da cidade (Entrevista com acadêmico, 4 de março de 2021). Entre outros, este exemplo destaca um dos desfechos principais das oficinas de ativistas - expandir e diversificar o conhecimento e as habilidades dos ativistas para melhor transitarem entre o que Miraftab (2009) chama de espaços de participação 'inventados' e 'convidados', variando de protestos a consultas públicas, para fazer reivindicações sobre a cidade.

\section{Transformando a educação em planejamento acessivel e estratégica}

Ao longo do tempo, o IIHS explorou muitos modelos operacionais para suas oficinas com ativistas e grupos de cidadãos - em parceria com ONGs, por nossa própria conta e como parte de um projeto de pesquisa KNOW (Knowledge in Action for Urban Equality) - para identificar e utilizar dispositivos pedagógicos fundamentais de maneira incremental, cujos aspectos principais são discutidos abaixo.

Deslocamento do(s) sítio(s) de aprendizagem: Antes de mais nada, esta experiência deriva do reconhecimento do ativismo como uma modalidade de prática urbana e um local produtivo para intercâmbio de 
conhecimento e coaprendizagem. A oficina inicial do IIHS Bangalore teve a participação principalmente de ativistas sênior que trabalham com organizações populares e movimentos sociais em suas próprias cidades e estados. Os engajamentos seguintes tornaram-se mais específicos ao contexto em colaboração com os ativistas participantes. Terra, moradia e planejamento são assuntos de Estado na Índia e as leis e as políticas variam entre os estados, tornando fundamental o trabalha em escala subnacional e por cidade. Os dois lugares onde a maioria das oficinas foi realizada são: Ranchi, em Jharkhand e Indore, em Madhya Pradesh. Não são grandes metrópoles da Índia, como Deli e Mumbai, onde a maioria da educação em urbanismo tem se concentrado até o momento. Realizar oficinas com ativistas nestas cidades também significava que muito mais moradores e ativistas comunitários poderiam participar sem se preocupar com o tempo e o custo de viagem até a sede do IIHS em Bangalore. Complementamos esta experiência de aprendizagem com uma pesquisa colaborativa nestas cidades para desenvolver conteúdo relevante e acessível (Anand, 2017; Anand; Deb, 2017; YUVA; IIHS, 2019).

Sobreposição e tradução de saberes e o currículo: O projeto e a oferta colaborativa de conteúdo específico ao contexto significava fazer as coisas de maneira diferente em comparação com uma sala de aula comum. O mais notável é que tivemos que superar dicotomias em linguagem e conhecimento ‘técnico'. Isso foi desafiador não porque alguns dos ativistas não compreendessem inglês ou termos técnicos, mas porque nenhum dos acadêmicos e pesquisadores tinha sido exposto ao planejamento em outro idioma, neste caso, hindi. Assim, a tradução tornouse uma parte importante desta experiência pedagógica entre idiomas (de inglês para hindi e vice-versa neste caso) e entre formas de saberes codificado e tácito. É importante destacar que aqui a tradução tem uma intenção em dois sentidos, tanto de abertura para acessibilidade e compreensão como de desafio ao poder implícito que o idioma oficial detém. Embora sejam feitas todas as tentativas para revelar e simplificar conceitos em hindi, os participantes também são incentivados a se tornar fluentes em determinados termos técnicos em inglês (por exemplo, categorias de uso da terra, zoneamento, violações) para articular suas reivindicações e estratégias perante as autoridades em um idioma que muitas vezes é usado para intimidar e excluir cidadãos.

As oficinas são planejadas para serem interativas, introduzindo camadas de conhecimento ao longo das sessões, a fim de trazer à tona a pluralidade de saberes presentes na sala. Começamos com as vivências dos participantes e as superpomos ao contexto de planejamento em suas cidades. $\mathrm{O}$ uso extensivo de jogos e exercícios como ferramentas pedagógicas introduz incrementalmente habilidades para controlar e navegar a complexidade. Os participantes localizam a si e seus assentamentos na cidade e em seu Plano; a partir daí, mergulhamos nos conteúdos e no processo do Plano. Vinculando teoria e prática, cada oficina termina com uma discussão sobre estratégias para garantir os direitos à moradia. Variam do curto ao médio e longo prazo, com base na sobre- 
posição das necessidades, aspirações e experiências dos participantes, bem como no panorama de planejamento e política em que mobilizam suas reivindicações. Múltiplas oficinas são conduzidas em cada cidade para permitir a aprendizagem contínua e reflexiva e sua consolidação ao longo do tempo.

Diversificando educandos e educadores: Como princípio pedagógico central desta abordagem, diversificar educandos e educadores força os limites das funções assumidas e das hierarquias implícitas no conhecimento e na prática de planejamento. Com base na tradução e no embasamento do conteúdo à aprendizagem entre experiências e o repensar sobre a pedagogia, as séries de oficinas também foram uma enorme experiência de coaprendizagem para nós, acadêmicos e investigadores no IIHS. Também têm sido um espaço para nos engajarmos paralelamente com pesquisa, ensino e prática, e refletir coletivamente sobre processos e desfechos de planejamento na Índia a partir destas experiências consolidadas, algo que é raro em programas acadêmicos usuais na Índia. No terceiro ano neste engajamento, também introduzimos alguns colegas do nosso Programa Urban Fellows (nove meses em tempo integral) como participantes destas oficinas de coaprendizagem. Assim, agora temos três tipos de educandos: educandos ativistas e comunitários; educandos acadêmicos; e educandos bolsistas, que trazem suas diferentes formações e experiências para estas oficinas.

Ao tratar a vivência como uma premissa básica para a expertise, tentamos criar um espaço de aprendizagem não-hierárquico em que todos são educandos e todos são educadores. Isto permite que todos nós aprendamos uns com os outros ao refletirmos sobre nossos próprios limites de conhecimento e vivência. Isso não quer dizer que tenhamos resolvido todas as questões, como as relações de poder, que foram discutidas previamente neste espaço, mas estamos constantemente tentando trabalhar ao estarmos cientes delas. Por exemplo, o recrutamento de ativistas como 'bolsistas de prática' do IIHS (Bhan apud Frediani et al., 2020) possibilitou institucionalizar sua função como profissionais e educadores. Da mesma forma, admitir nossas próprias limitações de idioma e conhecimento local nos ajuda, em certa medida, a não nos atravessarmos como instrutores ou especialistas, mas sim como coeducandos que têm muito a aprender com as vivências. O processo de cofacilitação e compartilhamento de funções entre acadêmicos, ativistas e bolsistas ajuda a criar um espaço de aprendizagem horizontal nas oficinas. Entretanto, também tem seu próprio conjunto de dinâmicas baseadas na idade, na experiência e no gênero, como qualquer modalidade de facilitação, que requerem mais reflexões na medida em que continuarmos com estas oficinas.

\section{Potenciais e desafios futuros da experiência de coaprendizagem}

Embora nossa atual escala e alcance sejam pequenos e seja cedo para medir os impactos destas oficinas em longo prazo, esta experiência pedagógica é promissora e já está mostrando sinais de abertura 
para educação e prática em planejamento. Alguns ativistas que participaram destas oficinas começaram a oferecer versões delas por conta própria e a desenvolver suas próprias caixas de ferramentas (Entrevista com acadêmico, 14 de janeiro de 2021). A ideia de recursos compartilhados é central para oferecer e multiplicar estas oficinas. Fora deste espaço, os ativistas também são convidados como docentes para outras oficinas de treinamento de curta duração e do programa de bolsas do IIHS. Esta multiplicidade de engajamentos com ativistas é essencial para trazer diferentes vozes e saberes para a educação e a prática em planejamento. Ativistas, acadêmicos e pesquisadores também conseguiram levar aprendizados desta experiência para outras iniciativas, como a campanha popular em torno do Plano Diretor em Deli chamado Main Bhi Dilli ${ }^{3}$.

Esta experiência de coaprendizagem tem seus desafios, especialmente quando começamos a pensar sobre escalabilidade e sustentabilidade em longo prazo. Por exemplo, a questão do idioma e da tradução continua sendo fundamental ao pensarmos sobre a escalabilidade e a translocalidade das oficinas e dos recursos. Refletir sobre o que pode ser levado e como, mantendo a integridade das oficinas e as características pedagógicas associadas, é especialmente relevante no contexto dos numerosos idiomas regionais na Índia. Outro conjunto de questões está vinculado a recursos e prioridades institucionais. O IIHS é uma instituição privada e, até agora, tivemos flexibilidade para desenvolver incrementalmente estas oficinas e financiá-las por meio de diferentes projetos. Embora seja útil ter este engajamento fora de um projeto único, ainda não temos uma sede em longo prazo para esta experiência na instituição, provocando reflexões sobre as possibilidades de institucionalizar estas oficinas para assegurar sua continuidade mesmo se as pessoas ou os projetos do IIHS mudarem. O fato de estarmos tentando arraigar esta pedagogia dentro e fora da instituição também significa que devemos continuar abertos a novos tópicos e oficinas que sejam úteis e relevantes para nossos educandos, com base em suas situação e experiência em mudança no campo. Não são processos fáceis ou diretos que um estabelecimento institucional de ensino superior imagine ou encontre recursos para desenvolvê-los.

\section{O que podemos aprender com ambas as experiências para resolver as injustiças epistêmicas por meio da pedagogia urbana?}

Ambas as experiências pedagógicas destacam como as instituições de ensino superior estão entre os muitos atores no âmbito urbano, ao invés de serem produtores e mediadores avalizados de conhecimento. Inseri-las em um 'ecossistema de saberes' (Santos, 2018) revela a necessidade de renegociar suas funções ao produzir, dar forma e usar seu conhecimento profissional juntamente com formas mais populares e experienciais de saberes de populações urbanas, ativistas, organizações da sociedade civil e outros. As repercussões pedagógicas deste 
reposicionamento são múltiplas, porque requerem não apenas questionar de quem é o conhecimento que conta, mas como os diferentes suportes do conhecimento - educandos e educadores dentro e fora da IES - se reúnem e aprendem uns com os outros. Ainda mais, de que maneira em termos testemunhais as crenças, os saberes e as afirmativas de diferentes atores e suas relações recebem credibilidade, e em termos hermenêuticos, de quem e quais conceitos e metáforas interpretativas fazem uma contribuição social para tratar o urbano como um espaço político. Assim, ativar as funções da IES dentro de um ecossistema de saberes requer uma atenção explícita e uma valorização e engajamento profundos do ecossistema de pedagogias subjacente.

É óbvio, mas ainda importante destacar, como ambas as experiências pedagógicas contestam o modelo de educação bancária (Freire, 1970), segundo o qual um detentor de conhecimento deposita um conhecimento singular nos cérebros de educandos que são tratados como recipientes vazios. A HIC-AL e o IIHS demonstram como os papeis de educando e educador, leigo e profissional são fundamentalmente questionados, indistintos e justapostos com a finalidade de fortalecer posições interseccionais, de intercâmbio e de validação de saberes urbanos pluralistas durante todo o processo de aprendizagem. Isto vai além de convidar ativistas ou movimentos sociais como palestrantes convidados para a sala de aula, ou estudantes para visitar bairros informais para estudá-los e chegar com soluções. Tal como na experiência do Taller de Vivienda, as pedagogias problematizadoras são usadas para coproduzir um diagnóstico transdisciplinar de problemas de moradia com movimentos populares e populações urbanas. Na experiência do IIHS, os ativistas fazem parte do corpo docente contratado do instituto, enquanto a equipe de funcionários acadêmicos tem sido um dos muitos grupos de educandos.

Ambas as experiências também são embasadas em táticas de aprendizagem translocal ao mobilizar experiências pedagógicas através das estruturas socioespaciais. Na experiência das escolas da HIC-AL, presta-se particular atenção à aprendizagem em rede e intergeracional, enquanto a abordagem adotada pelo IIHS enfoca a aprendizagem intra e intercidades. Com isso, o ecossistema de pedagogias adquire dimensões temporais e socioespaciais, permitindo o diálogo entre diversas formas e contextos de saberes para revelar valores, princípios e práticas em comum, bem como tornar visível, confrontar e deliberar sobre paradoxos e tensões. É este diálogo, e o espaço de tradução iterativa (McFarlane, 2011) entre vocabulários e hierarquias de idiomas codificados-etácitos, inglês-e-regionais, experiências urbanas-periféricas-e-rurais, disciplinares-e-vivenciadas, que permite construir um vocabulário compartilhado e um conjunto diversificado de práticas. A aproximação translocal de ambas as experiências também destaca o papel dos coletivos como redes e parcerias entre indivíduos e instituições, de modo que as práticas e as pedagogias emergentes sejam coletivamente assumidas, mediadas e facilitadas, e sustentadas e que viajem ainda mais através do tempo e das regiões por meio do diálogo com os outros, com 
recursos compartilhados, e com processos continuados de tradução e entrecompartilhamento.

A análise destacou o potencial destas experiências para contestar a injustiça epistêmica através do processo de coaprendizagem e coprodução de conhecimento, bem como pela criação de relações institucionais alternativas. A orientação para a 'produção social de moradia' em escolas da HIC-AL e para 'planejamento, moradia e informalidade urbana' em oficinas do IIHS é estratégica para desacomodar não apenas discursos dominantes de 'como o planejamento deve ser feito', mas para valorizar relações e práticas institucionais alternativas já existentes. Em seu atual avatar, com múltiplos grupos de educandos em oficinas do IIHS, podem ser traçados paralelos com estúdios colaborativos ou de coprodução de conhecimento mais amplo em que estudantes e pesquisadores trabalhem com as comunidades para produzir conhecimento e pesquisa. Entretanto, embora exista um reconhecimento dos saberes plurais em todas estas iniciativas, abordar fundamentalmente uma forma de injustiça epistêmica - isto é, tornar as relações 'testemunhais' entre falante e ouvinte mais iguais - a finalidade primeira das oficinas do IIHS é construir o conhecimento técnico de educandos ativistas conjuntamente com seus conhecimentos e experiências existentes.

Assim, as oficinas oferecem aos ativistas um vocabulário para ler e compreender os planos e para articular e comunicar seus conhecimentos e estratégias em um idioma que historicamente tem sido falado apenas por planejadores e formuladores de políticas profissionais. Por exemplo, um dos módulos nas oficinas do IIHS enfoca violações pela elite e violações pelo Estado para revelar a informalidade como modalidade ou urbanização (Roy, 2005), em vez de algo que está associado apenas com o pobre urbano e muitas vezes usado para estigmatizá-lo, marginalizá-lo e ameaçá-lo. Assim, tanto a produção social de moradia como o vocabulário de planejamento são indicativos de uma abordagem que fala diretamente à resolução de injustiças hermenêuticas. Isto, por sua vez, também tem o potencial de resolver a injustiça testemunhal em processos de planejamento e desenvolvimento urbano mais amplos. Com a experiência de coaprendizagem nas oficinas do IIHS e nas escolas da HIC-AL, foi desenvolvida uma sensibilização de educandos e educadores para abordar injustiças testemunhais e hermenêuticas em suas próprias pesquisas, ensino e prática. Por exemplo, conforme foi observado em Indore e no Main Bhi Dilli em Deli, existe uma mudança na maneira como os ativistas se engajam com os atores e os processos urbanos em seus contextos, fortalecendo seu ativismo por meio do uso estratégico de instrumentos de planejamento e de seu idioma para proteger e fazer reivindicações à cidade. No caso do Barrio Intercultural, o processo participativo desencadeou a autoidentificação dos moradores, que não fazem parte da comunidade indígena, como mestizos, e subsequentemente, levou a reflexões matizadas sobre suas identidades, ancestralidade e história colonial. 


\section{Como a mobilização da pedagogia crítica e o agenciamento epistêmico desafiam e deslocam a função de instituições de ensino superior?}

Nos esforços pluralizadores de experiências pedagógicas, tornase importante ser específico a respeito das contribuições e do valor adicionados por atores da universidade. Uma contribuição por integrantes da universidade na HIC-AL relaciona-se com sua habilidade para acreditar programas de aprendizagem, o que, por sua vez, adiciona visibilidade e legitimidade, primeiramente, à produção social de moradia como uma modalidade alternativa de desenvolvimento urbano, e, em segundo lugar, às qualificações de educandos urbanos que, de outra forma, poderiam não ter acesso ao ensino (superior) formal. Isto abre as possibilidades para profissionalizar saberes e habilidades urbanas que - embora amplamente praticados e populares - ainda são considerados aspectos secundários em debates acadêmicos mais amplos sobre urbanismo no Sul. Por exemplo, o trabalho com ativistas no IIHS beneficia não somente os ativistas em si para fortalecerem suas capacidades e habilidades de se engajar com processos formais do planejamento. Também demonstra aos participantes do programa de bolsas que o ativismo pode ser uma carreira para planejadores profissionais.

Além disso, as universidades são atores importantes ao alimentarem a relação dialógica entre teoria e prática que é fundamental para a pedagogia crítica, indo além das pedagogias puramente experienciais. Por exemplo, o Grupo de Trabalho para Fortalecimento da Capacidade da HIC-AL sintetiza os conceitos, os métodos e as práticas desenvolvidos entre as escolas e teoriza a partir da prática pedagógica popular para integrar estes processos de aprendizagem em espaços educacionais formais. Além disso, conforme mostramos em outra publicação (Wesely; Allen, 2019), não se pode negar que a maioria das universidades e instituições de educação em planejamento está localizada nas cidades, atribuindo a elas responsabilidade e oportunidade centrais para se transformarem em um aliado estratégico (popular ou informal) do desenvolvimento urbano. No exemplo da UAM-Xochimilco, esta importante função pública foi marcada desde sua fundação em 1974, engajando-se no campo do planejamento e arquitetura particularmente em questões relacionadas a sua localização periférica na Cidade do México e na moradia popular em bairros adjacentes. Por outro lado, o IIHS amplia como uma instituição privada de elite pode envidar esforços para pesquisar e ensinar a prática urbana igualitária no contexto de um país altamente desigual.

Quais estratégias, então, as universidades podem empregar para desacomodar os protocolos de ensino tradicionais e ativar seu potencial para criar e apoiar não apenas ambientes de aprendizagem mais iguais, mas também construir novas sensibilidades e suscetibilidades entre os educandos? Neste esforço, é fundamental diversificar o corpo docente e os educandos como reflexo do 'ecossistema de saberes' discutido acima. Entretanto, embora seja essencial trazer atores diferentes, isso não 
é suficiente. Conforme foi indicado por outros autores também (Mitlin et al., 2019), é necessário interrogar e desafiar as hierarquias tradicionais no ensino superior, inclusive as relações de poder entre e dentro do corpo docente acadêmico e não acadêmico. Da mesma forma, o local de aprendizagem necessita de diversificação e um reconhecimento explícito de seu poder e agenciamento. Por exemplo, a experiência do IIHS e do Taller de Vivienda mostra que é necessário que as instituições de nível superior reconheçam múltiplas modalidades de aprendizagem e prática dos educandos, além de ir aonde os educandos estão, e não apenas vice-versa.

As experiências de aprendizagem da HIC-AL e do IIHS chamam atenção para pedagogias que sejam iterativas e dialógicas e que sejam embasadas na ideia de práxis, tradução, saberes plurais e ação estratégica. Como modos de pensar, sugerem epistemologias que falam ao propósito da educação como um espaço de transformação, ação, e de dar forma ao mundo em um sentido freireano. Usar estas epistemologias como um ponto de entrada para reposicionar a finalidade pedagógica, em vez de a instituição em si, é útil para abrir novos locais e arranjos entre formas institucionais de ensino superior e movimentos sociais - como uma ponte da 'pluriversidade' e da 'subversidade'. Estes sítios de ligação de ensino superior mapeiam e valorizam a demanda além das metas do mercado para desafiar estrategicamente as injustiças epistêmicas. No caso do IIHS, a demanda pelos espaços pedagógicos surge dos ativistas e das comunidades, enquanto os meios para sustentá-los são criados a partir de diferentes fontes financiadoras. Na experiência da HIC-AL, os movimentos sociais e as organizações comunitárias trabalham estrategicamente com as universidades rumo a metas pedagógicas coletivas. Significativamente, as experiências discutidas sugerem uma influência sobre processos e estruturas institucionais, bem como sobre a economia política de práticas fora da universidade. Apontam para formas de alianças e práticas de aprendizagem, dentro e fora da universidade, por meio de saberes e noções de escala assumidas coletivamente que se estendem através das relações do que Santos (2018) sugere como pluriversidade e subversidade.

\section{Conclusão}

A análise comparativa de duas experiências de aprendizagem oferece insights sobre táticas e estratégias inovadoras das pedagogias críticas do IIHS e da HIC-AL que desacomodam a ideia da universidade e reformulam compreensões e hierarquias de conhecimento e prática. $\mathrm{O}$ artigo prestou particular atenção às populações urbanas, movimentos sociais e ativistas nos campos da habitação e da produção social de moradia epistemicamente marginalizados na Índia e na América Latina, revelando núcleos de mudança e múltiplos pontos de entrada para reformular as instituições de ensino superior como um entre muitos atores e instituições. Ambas as experiências pedagógicas sugerem que é imperativo promover simultaneamente a pluriversidade e a subver- 
sidade para criar espaços e habilidades para atores que, muitas vezes, estão marginalizados em um ecossistema de pedagogias urbanas e, assim, para contribuir para uma combinação de recursos epistêmicos que reflitam as diversas teorias e práticas do urbanismo do Sul.

A experiência de coaprendizagem do IIHS exemplifica um esforço rumo à pluriversidade. As escolas da HIC-AL são produtos de esforços de subversidade no sentido de que, desde o início, as universidades são de fato uma entre outros atores. A HIC-AL se engaja em pedagogias em rede com plena consciência e vocação para usar seu poder contra-hegemônico na totalidade. Ainda assim, ambos os processos de reconstrução - a pluriversidade e a subversidade - se encontram em seu destino e objetivos radicais. O primeiro constitui um esforço significativo para reinventar a universidade a partir de dentro, em que 'de dentro' significa ser, saber e aprender com os outros. Mais fundamentalmente, requer a 'abertura de espaço' institucional para outros mobilizadores importantes de conhecimento e aprendizagem consolidada, como os ativistas pelos direitos humanos nas experiências examinadas. A proposição radical encontra-se aqui no esforço de criar um 'nós' institucional, encarando de frente as mudanças radicais na economia política das IESs que, de outra maneira, as levam a intencionalmente reproduzir injustiças epistêmicas.

No caso da HIC-AL, o objetivo em comum que orienta as escolas é a formação de modos subversivos de fazer e saber e de articular estas maneiras para efetuar a mudança transformadora. Aqui, diferentemente da experiência do Taller de Vivienda, a ênfase não é tanto em transformar as IESs e sua economia política, mas sim em preservar a capacidade dos esforços pedagógicos em rede para uma forte incidência política, enquanto olhos e ouvidos são mantidos simultaneamente atentos à experiência coletiva consolidada de injustiça epistêmica e do mapa relacional em movimento que oferece resistência e aberturas para efetuar uma mudança radical.

Os esforços para criar a pluriversidade e a subversidade não estão em conflito entre si, mas sim convergem nos locais de luta que objetivam promover a justiça epistêmica. Posicionam as pedagogias urbanas radicais e transformadoras como um campo da prática moral e política, cuja significância vai além do urbano como um local de aprendizagem e clama pelo forjar de uma compreensão e prática reformuladas do urbanismo do Sul em dois aspectos. Primeiro, ao expandir a mobilização do agenciamento epistêmico para múltiplos atores urbanos, inclusive instituições de ensino superior, movimentos sociais e ativistas. Em segundo lugar, ao explorar como as pedagogias críticas para a transformação urbana - como práticas morais e políticas - abordam as injustiças epistêmicas que perpetuam práticas de planejamento urbano coloniais, excludentes e disciplinares ${ }^{4}$.

Traduzido por Ananyr Porto Fajardo

Recebido em 06 de junho de 2021 Aprovado em 05 de agosto de 2021 


\section{Notas}

$1 \mathrm{https} / / /$ hic-al.org

2 https://iihs.co.in

3 https://www.mainbhidilli.com

4 Agradecimentos: Gostaríamos de agradecer a todos os entrevistados e participantes das oficinas que tornaram possíveis estas experiências e reflexões. Também somos muito gratas aos revisores anônimos por seus valiosos comentários e sugestões e a Gautam Bhan, Neha Sami e Shriya Anand, do Indian Institute for Human Settlements, por suas contribuições às versões iniciais deste artigo. Finalmente, um enorme agradecimento a Tristan McCowan e a Gunther Dietz por terem organizado este número especial e terem sediado uma oficina em fevereiro de 2021, o que ajudou a formatar este trabalho. Este artigo faz parte do programa de pesquisa Knowledge in Action for Urban Equality (KNOW), apoiado pelo UKRI (UK Research Innovation) por meio da Global Challenges Research Fund GROW Call. Referência do Financiamento: ES/ P011225/1.

\section{Referências}

ADDIE, Jean-Paul D. Urban(izing) University Strategic Planning: An Analysis of London and New York City. Urban Affairs Review, v. 55, n.6, p. 1612-1645, 2019.

ALLEN, Adriana; LAMBERT, Rita; YAP, Christopher. Co-learning the city: towards a pedagogy of poly-learning and planning praxis. In: BHAN, Gautam; SRINIVAS, Smita; WATSON, Vanessa (Ed.). The Routledge Companion to Planning in the Global South. New York: Routledge, 2018. P. 355-367.

ALLEN, Adriana; WESELY, Julia. Urban pedagogies: How do we learn and practice urban equality? In: ALLEN, Adriana; LAMBERT, Rita; YAP, Christopher. In the KNOW 3. London: Knowledge in Action for Urban Equality, 2020.

ANAND, Geetika. Planning, 'Violations,' and Urban Inclusion: A Study of Ranchi. New Delhi: YUVA; IIHS, 2017.

ANAND, Geetika; DEB, Anushree. Planning, 'Violations,' and Urban Inclusion: A Study of Bhubaneswar. New Delhi: YUVA; IIHS, 2017.

ARBESÚ GARCÍA, Maria Isabel; ORTEGA ESPARZA, Victor M. Teoría y Práctica del Sistema Modular en la Universidad Autónoma Metropolitana, Unidad Xochimilco. Perspectiva Educacional, n. 47, p. 33-57, 2006.

BHAN, Gautam. Planned Illegalities. Housing and the 'Failure' of Planning in Delhi: 1947-2010. Economic and Political Weekly, v. 47, n. 24, p. 58-70, 2013.

BHAN, Gautam. Notes on a Southern urban practice. Environment \& Urbanization, v. 31, n. 2, p. 639-654, 2019.

BOIDIN, Capucine; COHEN, James; GROSFOGUEL, Ramón. Introduction: From University to Pluriversity: A Decolonial Approach to the Present Crisis of Western Universities. Human Architecture: Journal of the Sociology of Self-Knowledge, v. 10, n. 1, p. 1-6, 2012.

BONI, Alejandra; VELASCO, Dani. Epistemic Capabilities and Epistemic Injustice: What is the Role of Higher Education in Fostering Epistemic Contributions of Marginalized Knowledge Producers? Global Justice: Theory, Practice, Rhetoric, v. 12, n. 1, p. 1-26, 2019. 
CALDEIRA, Teresa. Peripheral urbanization: Autoconstruction, transversal logics, and politics in cities of the global south. Environment and Planning D: Society and Space, v. 35, n.1, p.3-20, 2017.

DAVOUDI, Simin; PENDLEBURY, John. Centenary Paper: The Evolution of Planning as an Academic Discipline. Town Planning Review, v. 81, p. 613-646, 2010. DOTSON, Kristie. Tracking epistemic violence, tracking practices of silencing. Hypatia, v. 26, n. 2, p. 236-257, 2011.

ENET, Mariana; ROMERO, Gustavo. Diseño Participativo Sustentable del Hábitat Como Herramienta de la Producción y Gestión Social del Hábitat y Para el Ejercicio de Derechos. Mexico City: UNAM, HIC-AL. 2019

FREDIANI, Apsan et al. Institutional capabilities towards urban equality. KNOW Working Paper Series, London, n. 4, 2020.

FREIRE, Paulo. Pedagogy of the Oppressed. New York: Continuum, 1970.

FRICKER, Miranda. Epistemic Injustice: Power and the Ethics of Knowing. Oxford: Oxford University Press, 2007.

GIROUX, Henry. Youth, Higher Education, and the Crisis of Public Time: Educated Hope and the Possibility of a Democratic Future. Social Identities, v. 9, n. 2, p. 141-168, 2003.

GIROUX, Henry. On Critical Pedagogy. New York: Continuum International Publishing Group, 2011.

GORE, Jennifer M. The struggle for pedagogies: critical and feminist discourses as regimes of truth. New York: Routledge, 1993.

HABITAT INTERNATIONAL COALITION. Habitat International Coalition and the Habitat Conferences 1976 - 2016. Barcelona: Creative Commons, 2018.

hooks, bell. Teaching community: A pedagogy of hope. New York: Routledge, 2003.

KANE, Liam. Forty years of popular education in Latin America. In: HALL Budd L.; CLOVER Darlene E.; CROWTHER Jim; SCANDRETT, Eurig (Ed.). Learning and Education for a Better World. International Issues in Adult Education. Rotterdam: Sense Publishers, 2012. P. 69-83.

KIRK, Chris Michael et al. The empowering schools project: Identifying the classroom and school characteristics that lead to student empowerment. Youth \& Society, v. 49, n. 6, p. 827-847, 2007.

LYNN, Marvin. Inserting the 'Race' into Critical Pedagogy: An analysis of 'race' based epistemologies'. Educational Philosophy and Theory, v. 36, n. 2, p. 15365, 2004.

MAHADEVIA, Darshini; BHATIA, Neha. Urban Planning Education for Inclusive Cities: Global and Indian Perspectives. Report prepared for the Building Inclusive Urban Communities (BInUCom) project, funded by Erasmus + programme of the European Union. Europe, 2018.

MAHADEVIA, Darshini; JOSHI, Rutul. Subversive Urban Development in India: Implications on Planning Education. Working Paper - 1. Ahmedabad: Centre for Urban Equity; CEPT University, 2009.

MARTÍNEZ-VARGAS, Carmen. Decolonising Higher Education Research: From a University to a Pluriversity of Approaches. South African Journal of Higher Education, v. 34, n. 2, p. 112-128, 2020.

MARZIONI, Guillermo Javier. Hábitat Popular. Encuentro de Saberes. Buenos Aires: nobuko, 2012.

Educação \& Realidade, Porto Alegre, v. 46, n. 4, el18080, 2021. 
MCFARLANE, Colin. The city as a machine for learning. Transactions of the Institute of British Geographers, v 36, n 3, p. 360-376, 2011.

MCFARLANE, Colin. Learning from the city: a politics of urban learning in planning. In: BHAN, Gautam; SRINIVAS, Smita; WATSON, Vanessa (Ed.). The Routledge Companion to Planning in the Global South. New York: Routledge, 2018. P. 323-333.

MIRAFTAB, Faranak. Insurgent planning: Situating radical planning in the Global South. Planning Theory, v. 8, p. 32-50, 2009.

MITLIN, Diana. With and beyond the state - co-production as a route to political influence, power and transformation for grassroots organizations. Environment and Urbanization, v. 20, n. 2, p. 339-360, 2008.

MITLIN, Diana et al. Knowledge matters: the potential contribution of the coproduction of research to urban transformation. Global Development Institute Working Paper series, Manchester, The University of Manchester, n. 039, 2019.

ORTIZ OCAÑA, Alexander; ARIAS LÓPEZ, María Isabel. Hacer decolonial: desobedecer a la metodología de investigación. Hallazgos, v. 16, n. 31, p. 147$166,2018$.

PARNELL, Susan; PIETERSE, Edgar; WATSON, Vanessa. Planning for cities in the global South: an African research agenda for sustainable human settlements. Progress in Planning, v. 72, p. 233-241, 2009.

PARNELL, Susan; ROBINSON, Jennifer. (Re)theorizing Cities from the Global South: Looking Beyond Neoliberalism. Urban Geography, v. 33, n. 4, p. 593-617, 2012 .

RODRÍGUEZ, María Carla. Algunos efectos de impulsar políticas de producción autogestionaria del hábitat. El Movimiento de Ocupantes e Inquilinos. Revista Debate Público. Reflexion de Trabajo Social, v. 6, p. 155-168, 2013.

ROY, Ananya. Urban informality: Towards an epistemology of planning. Journal of the American Planning Association, v. 71, n. 2, p. 147-158, 2005.

SANTOS, Boaventura de Sousa. The End of The Cognitive Empire: The Coming of Age of Epistemologies of the South. Durban \& London: Duke University Press, 2018.

SWARTZ, Rebecca; IVANCHEVA, Mariya; CZERNIEWICZ, Laura; MORRIS, Neil Peter. Between a rock and a hard place: Dilemmas regarding the purpose of public universities in South Africa. Higher Education, v. 77, n. 4, p. 567-583, 2019.

TARLAU, Rebecca. From a language to a theory of resistance: Critical pedagogy, the limits of 'framing', and social change. Educational Theory, v. 64, n. 4, p. 369392, 2014.

UN-HABITAT. Global Report on Human Settlements 2009: Planning Sustainable Cities. London: Earthscan, 2009.

WATSON, Vanessa. Seeing from the South: Refocusing Urban Planning on the Globe's Central Urban Issues. Urban Studies, v. 46, n. 11, p. 2259-2275, 2009.

WATSON, Vanessa. Inclusive Urban Planning for the Working Poor: Planning Education Trends and Potential Shift. WIEGO Working Paper, n. 21, 2011.

WATSON, Vanessa; ODENDAAL, Nancy. Changing planning education in Africa: The role of the association of African planning schools. Journal of Planning Education and Research, v. 33, n. 1, p. 96-107, 2013. 
WESELY, Julia et al. Generative Pedagogies from and for the Social Production of Habitat: Learning from HIC-AL School of Grassroots Urbanism. plaNext next generation planning, online first, 2021.

WESELY, Julia; ALLEN, Adriana. De-Colonising Planning Education? Exploring the Geographies of Urban Planning Education Networks. Urban Planning, v. 4, n. 4, p. 139-151, 2019.

YUVA; IIHS. Examining the 'Slum' in the Narratives of Urban Planning Processes: Study and Capacity Building Based in Indore. City Say. Navi Mumbai: Youth for Unity and Voluntary Action, 2019.

ZÁPOTOČNÁ, Ol'ga. Literacy as a tool of civic education and resistance to power. Human Affairs, v. 22, n. 1, p. 17-30, 2012.

Geetika Anand é doutoranda na Universidade da Cidade do Cabo, com foco em biografias de prática de desenvolvimento urbano. Trabalha junto ao Indian Institute for Human Settlements desde 2010. Atualmente é pesquisadora no Programa Knowledge in Action for Urban Equality (KNOW).

ORCID: https://orcid.org/0000-0002-3971-0523

E-mail: ganand@iihs.ac.in

Ruchika Lall é Consultora (Acadêmica e de Pesquisa) no Indian Institute for Human Settlements. Trabalha como pesquisadora no Programa KNOW sobre questões de desigualdade urbana e sua relação com a educação urbana. ORCID: https://orcid.org/0000-0001-6313-9390

E-mail: ruchikal@iihs.ac.in

Julia Wesely é Pós-doutoranda no Programa KNOW na Bartlett Development Planning Unit (DPU), University College London (UCL). Sua pesquisa atual procura compreender e apoiar as pedagogias críticas para a abordagem da injustiça epistêmica e da desigualdade urbana em cidades latinoamericanas, africanas e asiáticas.

ORCID: https://orcid.org/0000-0003-1691-9620

E-mail: julia.wesely@ucl.ac.uk

Adriana Allen é Professora de Planejamento do Desenvolvimento e Sustentabilidade Urbana na (DPU), UCL e Presidente da Habitat International Coalition (HIC). Adotando uma perspectiva feminista de ecologia política, seu trabalho explora as interfaces entre práticas cotidianas de fazer a cidade e intervenções planejadas e sua capacidade de gerar espaços, lugares e relações sociais transformadores.

ORCID: https://orcid.org/0000-0001-6215-5962

E-mail: a.allen@ucl.ac.uk

Editor-chefe: Luís Armando Gandin

Este é um artigo de acesso aberto distribuído sob os termos de uma Licença Creative Commons Atribuição 4.0 Internacional. Disponível em: <http:// creativecommons.org/licenses/by/4.0>. 